\title{
Drilling of Holes in Aluminum Matrix Composites at Dry and with the Minimum Quantity Lubrication of the Cutting Zone
}

\author{
P. Karolczak ${ }^{a, *}$, D. Porośa, H. Skowronek ${ }^{a}$ \\ aWrocław University of Science and Technology, Faculty of Mechanical Engineering, Ignacego Łukasiewicza 5 \\ Street, 50-371 Wrocław, Poland.
}

Keywords:

Composite materials

Drilling

Surface roughness

Roundness deviation

Cutting forces

Chips

* Corresponding author:

Paweł Karolczak

E-mail: pawel.karolczak@pwr.edu.pl

Received: 29 June 2021

Revised: 9 August 2021

Accepted: 18 August 2021

\begin{abstract}
A B S T R A C T
Holes in metal matrix composites can be created by unconventional techniques such as EDM or laser drilling. However, these methods do not guarantee the quality of the holes, the production efficiency. The work carried out conventional drilling studies of aluminum matrix composite reinforced with ceramic fibers and the nonreinforced matrix. The tests were made dry and under conditions of minimum quantity lubrication (MQL) of the cutting zone. Oil mist was applied external. The measured and observed machinability indicators were surface roughness, cutting force, hole shape error, and chip shape. It was found that the use of oil mist in drilling improves the shape quality and surface of the holes. The positive effect of lubrication decreases with increased drilling feed. Oil mist slightly reduces cutting resistance and does not change the shape of the chips. It is shown that by drilling holes in aluminum matrix composite under conditions of minimal quantity lubrication, it is possible to achieve such a quality that it is possible to eliminate roughing. An additional advantage of using oil mist is a smaller dispersion of test results, which shows that the treatment with minimal lubrication is more stable.
\end{abstract}

(C) 2021 Published by Faculty of Engineering

\section{INTRODUCTION}

Currently, the use of conventional materials, such as aluminum alloys in the manufacture of means of transport, becomes inefficient [1]. The answer to the high demands to construction materials can be, for example, composites. Composites are divided according to the matrix material into three groups: metal-matrix composites, polymer-matrix composites, and ceramic-matrix composites [2].
Among metal matrix composites the ones based on aluminum are widely used in the many industries, including aerospace industry [3]. The reinforcing material in these composites is usually a ceramic compound, e.g. $\mathrm{SiC}$ and $\mathrm{Al}_{2} \mathrm{O}_{3}$, and graphite, in the form of particles or fibres [4]. First, a composite needs to be produced using powder metallurgy or casting [5]. Then, through machining, the composite is endowed with appropriate final dimensions. The main problem during machining is 
the abrasive action of the reinforcement, resulting in high tool wear. According to the literature on the subject, a long useful tool life can be ensured through the use of expensive tools made of polycrystalline diamond (PCD) [6]. Another problem in the drilling of holes is posed by delamination, mainly of polymer composites, which can also occur (in the form of burrs) in the drilling of metal matrix composites [7]. Another problem is meeting the high quality requirements concerning the dimensions, shape, and surface roughness of holes and the absence of surface and near-surface defects. For this purpose such variables as: tool material, tool geometry and cutting parameters must be carefully matched. Research shows that in order to minimize drilling forces, surface roughness, tool wear, and burr size in the machining of the most popular composites, a minimum feed rate and a possibly high cutting speed should be matched up. From the above parameters, the feed rate is most closely correlated with the machining effects [8]. This correlation does not change with the diameter of the drilled hole [9]. Cooling and lubrication conditions have a particularly strong effect on the drilling of composites. Since these conditions play a significant role, they should be precisely designed. Basically, dry drilling can be carried out, but the tool life and the quality of the hole are not satisfactory. Therefore, a machining fluid should be used [10]. In many branches of industry, immersion lubrication is used, but this increases manufacturing costs and poses difficulties in the disposal of the wastes, which are not friendly to the environment. Various innovative lubrication and cooling methods, for example minimum quantity lubrication (MQL) and cryogenic cooling, are used to effectively reduce temperature, which intensifies build-up and thus increases cutting forces, tool wear, and surface roughness [11]. Research shows that the use of these methods reduces the delamination of polymer matrix composites and improves the roundness and roughness of the drilled holes while increasing tool life [12]. However, other studies showed that the use of MQL could contribute to the delamination of polymer composites [13]. This was due to the brittle cracking of the fibres and to the fact that oil mist, instead of forming a protective film, would penetrate to the place of contact between the fibres and the matrix, filling all the voids in the bond between the composite's components. Such problems are not encountered in the machining of aluminum-matrix composites. The work [14] investigated a nanocomposite based on 7075 aluminum alloy. Tests were carried out dry turning and with minimal lubrication. A positive effect of the use of MQL has been observed. Machining under oil mist lubrication conditions contributed to a reduction in the forces generated during machining, as the lubricant, even when fed in small quantities, helps to reduce heat and friction. The preferred condition for achieving minimal surface roughness when machining aluminum matrix composites is a low feed rate combined with a high cutting speed and the MQL environment [14]. Drilling of the aluminum alloy 2024-T351 with the use of MQL, dry and with air cooling was investigated in [15]. In the drilling tests, uncoated tungsten carbide drills with a diameter of $4 \mathrm{~mm}$ and a point angle of $135^{\circ}$ were used. The oil mist was fed internally. It has been noticed that the oil mist does not facilitate the evacuation of chips, and therefore the temperature near the outer corner is higher. On the other hand, the temperature difference between the center and the outer corner of the drill in MQL drilling is lower than in dry and air-cooling environments. MQL also reduces the build-up edge. Articles [16,17] investigated the effectiveness of using external MQL lubrication when drilling holes in magnesium alloys. In [16], dry drilling was compared with flood cooling and two types of MQL. These were a distilled water spray known as $\mathrm{H}_{2} \mathrm{O}-\mathrm{MQL}$ and a fatty acid-based agent. The maximum temperature generated in the workpiece during MQL drilling did not exceed that produced during flooded drilling. Due to this, there was no intense build-up. This resulted in a lower drilling force and torque when drilling with MQL compared to dry drilling. In [17], the UNS M11917 alloy was tested. The tests were carried out using two HSS drills with a point angle of $118^{\circ}$ and $135^{\circ}$. The cutting data selected were low to prevent ignition of the chip. It was found that during dry drilling it is possible to obtain a low roughness of $R a=0.9 \mu \mathrm{m}$. However, the use of an oil mist allows the roughness to be reduced even to $R a$ $=0.13 \mu \mathrm{m}$. The angle of the apex also has a significant influence. The smaller the one, the better the roughness. In [18] the lubrication efficiency of MQL in the drilling of the Ti6Al4V alloy was assessed. They were compared with flood cooling and air cooling. It was found that the lubrication of MQL with synthetical grease or palm oil allows the reduction of the cutting forces and the increase of the service tool life in relation to dry machining. The positive impact was assessed at a level similar to that in the case of flood cooling. Furthermore, surface roughness can be effectively improved 
during the treatment of the Ti6Al4V alloy by using oil mist [19]. Reduced cutting forces and roughness due to the use of MQL in comparison with dry drilling can be achieved not only when machining light alloys or composites, but also in stainless steels drilling [20].

If tool wear is high and drilling cannot be used, laser and electrical discharge machining (EDM) can be employed to make holes in composites. These techniques offer several advantages, the main being no expensive tool wear. But they also have certain limitations. Similarly as in conventional machining, appropriate machining conditions must be adopted for EDM in order to obtain satisfactory hole quality and good machining efficiency. Research shows that electrical discharge drilling (EDD) ensures better machining conditions and is more stable than EDM [21]. In the case of rotary electrical discharge drilling, the parameters having a bearing on the efficiency of the process are: peak current, tool polarity and tool rotational speed [22]. Copper electrodes ensure the highest efficiency while brass electrodes ensure the lowest hole roughness [23]. Laser drilling seems to be an ideal method for making small-diameter (up to $1 \mathrm{~mm}$ ) holes. Depending on the hole's size and shape and the quality requirements, four kinds of laser drilling are used in industry, i.e. spiral drilling, trepan drilling, single-pulse drilling and percussion drilling. Each of the techniques has its advantages and disadvantages and its application depends on the efficiency and hole quality requirements and whether the particular kind of laser can actually be used [24]. It has been demonstrated that millisecond pulse lasers can be used to drill holes in aluminum matrix composites, obtaining acceptable quality of the holes. It has also been found that the efficiency of this process is higher than in the case of drilling in metals and alloys [25]. Considering that electrical discharge and laser machining can make the reinforcement crack in both the surface layer and deeper inside the material if excessively high machining parameters are set, ways of avoiding this adverse effect are sought. In the case of laser drilling, the use of argon as an auxiliary gas makes it possible to minimize the thickness of the altered surface layer and at the same time to improve the shape of the hole [25].

Analyzing the literature sources, it can be noticed that making holes in composite materials is difficult, especially under dry machining conditions. During the process delamination occurs, creates built-up edge and burrs deteriorate the quality of the holes. The reinforcement is abrasive to the blade and wears it down. Unconventional methods of drilling holes are known and investigated. Despite their increasing share, conventional drilling remains the main method of making holes in composite materials, especially larger-diameter holes. The literature shows that the efficiency of drilling holes can be increased by using flood cooling, air cooling as well as MQL cooling. Compared to flood cooling, the MQL method is more ecological and should be constantly developed. In the literature, there are studies on the effectiveness of the use of MQL in machining, including drilling, titanium, aluminum, magnesium alloys and polymer composites. However, there is a lack of extended and comprehensive research on drilling aluminum composites under MQL lubrication conditions. The above were the reasons for undertaking the research presented in this paper.

\section{MATERIALS AND METHODS}

Two materials were subjected to tests. The first of them was an aluminum matrix composite reinforced with long ceramic fibres. The second (comparative) material was the aluminum alloy constituting the matrix of the composite. It was alloy AlSi9Mg which belongs to complex casting aluminum-silicon alloys (silumins) [26]. Silicon lowers hot brittleness and improves castability while the magnesium addition enables precipitation hardening. Owing to this AlSi9Mg is suitable for solution heat treatment and ageing [27]. Moreover, this material is characterized by good resistance to corrosion and to the action of seawater [27]. It is also characterized by very good weldability and machinability [27].

Saffil ceramic fibres are one of the materials most often used to reinforce aluminum-matrix composites [28]. They are composed of $\mathrm{Al}_{2} \mathrm{O}_{3}$ (9697\%) and $\mathrm{SiO}_{2}(3-4 \%)$ [29]. They belong to a group of high-strength materials as they are characterized by good resistance to high temperatures, high tensile strength and a high modulus of elasticity [30]. The properties of Saffil fibres are presented in table 1 . These are approximate values and can differ depending on many factors, e.g. on the manufacturing method. 
Table 1. Properties of saffil fibres [30].

\begin{tabular}{|c|c|c|c|c|c|}
\hline 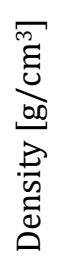 & 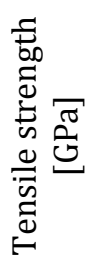 & 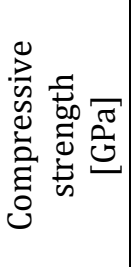 & 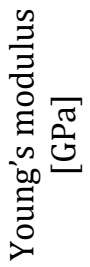 & 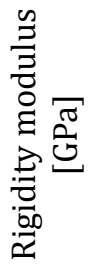 & 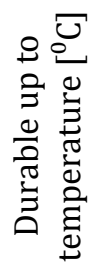 \\
\hline 3.7 & 1.8 & 6.9 & 300 & 122 & 1600 \\
\hline
\end{tabular}

The tested composite was produced by squeeze casting. The process was divided into two stages. First a Saffil fibre block was created by mixing Saffil fibres with a silica binder, pouring the mixture into a mould, filtering off the solution, drying the profile with hot air and firing it at the temperature of $950^{\circ} \mathrm{C}$. Then the ceramic block was infiltrated with liquid metal as follows: the heated up to $700^{\circ} \mathrm{C}$ block was placed in a mould and liquid aluminum was poured over it, then pressure was exerted onto the surface of the metal by means of a ram. The ram and the mould containing the block were heated up to the temperature of $150-300^{\circ} \mathrm{C}$. In this way an aluminum composite characterized by good properties was obtained [29]. The HB hardness of the obtained composite is $50 \%$ higher, its tensile strength $R_{m}$ as much as $60 \%$ higher and offset yield point $R_{0,2}$ is $40 \%$ higher in comparison with the matrix material. Moreover, the composite is four times more abrasion resistant than the matrix. Figure 1 shows a metallographic polished section of the tested composite.

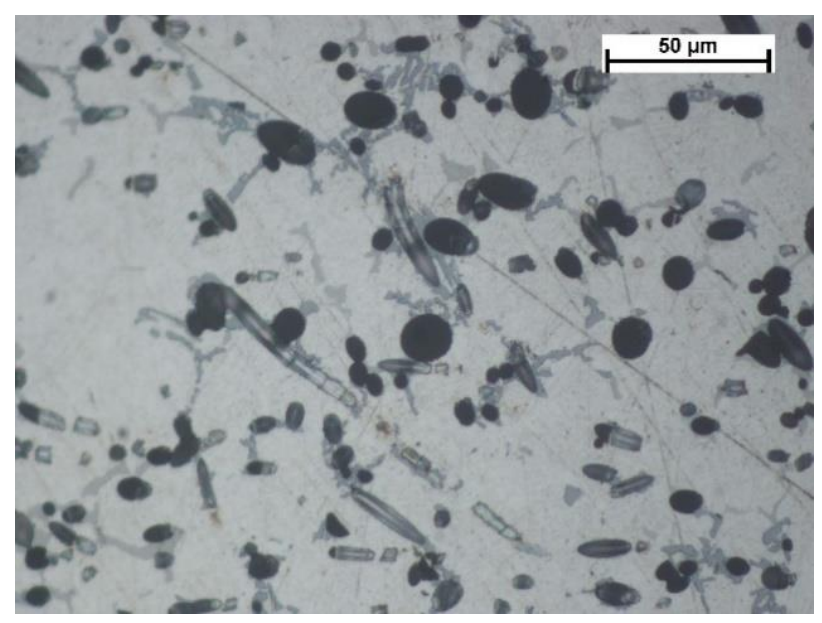

Fig. 1. Metallographic polished section of tested composite.

Drilling tests were carried out using a Csepel RF 50/1250 radial drilling machine. Holes were drilled with a $\phi 9.96537$ VHM TiAlN drill bit. The drill bit was made of carbides of refractory metals, mainly titanium and tungsten, sintered with cobalt as a metal binder. The coating had a thickness of 5-10 $\mu \mathrm{m}$ according to the drill manufacturer's data. Three cutting speeds: $v_{c}=$ 11,22 and $44 \mathrm{~m} / \mathrm{min}$ and four feed rates: $f=0.05$, $0.075,0.112$ and $0.17 \mathrm{~mm} / \mathrm{rev}$. were adopted.

The test stand was equipped with an Accu-Lube Minibooster for MQL. The cooling-lubricating fluid in the form of aerosol was externally fed by one nozzle situated close to the drill bit. The air operating pressure was 7 bar and the fluid flow rate was $180 \mathrm{ml} / \mathrm{h}$. An oil with the designation $\mathrm{Lb}$ 5000 was used to generate an oil mist. This oil can be used for medium to heavy machining of all materials. Its properties are shown in the table 2 . The drilling stand with the oil mist feed nozzle is shown in figure 2 .

Table 2. Properties of LB 5000 oil used to generate an oil mist.

\begin{tabular}{|c|c|c|c|c|c|}
\hline \multirow{2}{*}{$\begin{array}{c}\text { LB } \\
5000 \\
\text { oil }\end{array}$} & 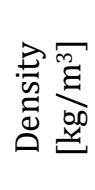 & 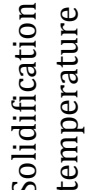 & 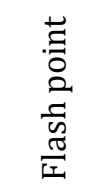 & 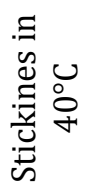 & 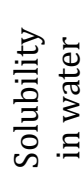 \\
\hline & 850 & $5^{\circ} \mathrm{C}$ & $190^{\circ} \mathrm{C}$ & 18 & no \\
\hline
\end{tabular}

The feed forces and the cutting torque were measured during the machining process. The measuring circuit consisted of a KISTLER 9257A piezoelectric force gauge, a KISTLER 5011 electric signal amplifier and a Tektronix TDS 5054B oscilloscope.

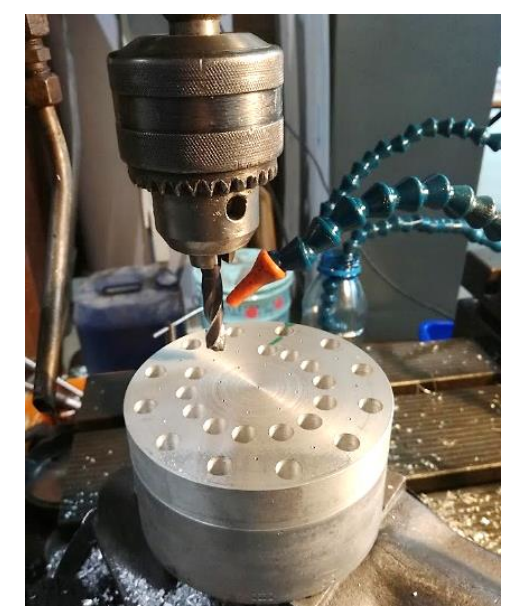

Fig. 2. Drilling stand with external oil mist feeding.

The quality of the drilled holes was assessed through measurements of shape (roundness) errors and surface roughness. Roundness was 
measured by means of a Taylor Hobson Talyrond 265 device (fig. 3). A Mitutoyo Surftest SV-3200 roughness meter (fig. 4) was used to measure surface roughness.

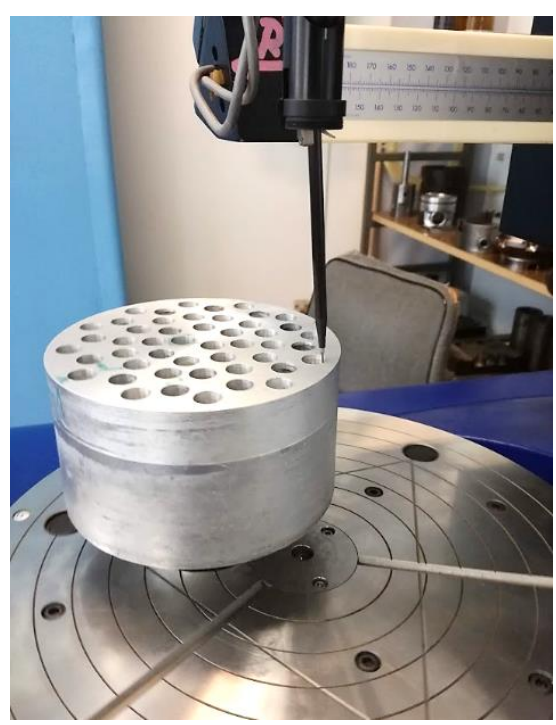

Fig. 3. Taylor Hobson Talyrond 265 for measuring shape errors.

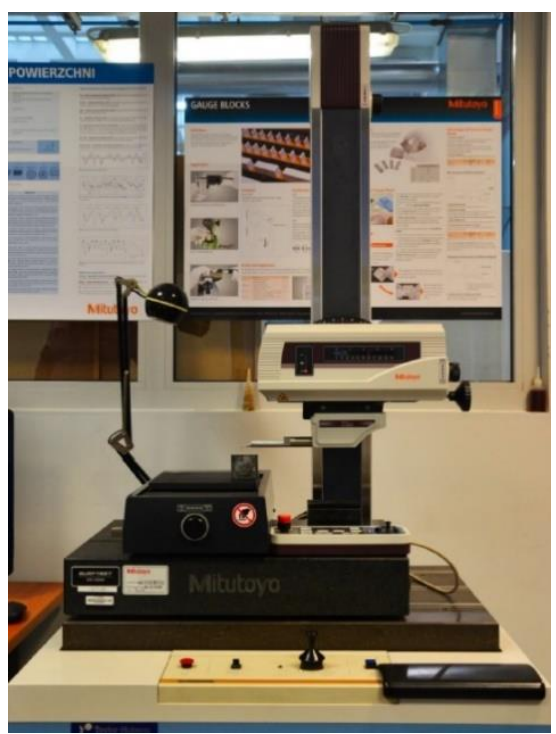

Fig. 4 Mitutoyo surftest SV-3200 for measuring surface roughness.

\section{RESULTS AND DISCUSSION}

The 2D roughness measurements were carried out along a measuring length of $4.8 \mathrm{~mm}$. To separate roughness from surface undulations and shape errors, the measured surfaces were filtered by means of a Gaussian filter with a cut-off of 0.8 $\mathrm{mm}$. This filter was selected consistent with the assumed surface roughness. If higher roughness is expected, a $2.5 \mathrm{~mm}$ filter should be used. Since blind holes with a small depth were drilled and to obtain five roughening sample cut-offs a measuring length of at least $12.5 \mathrm{~mm}$ would be needed, the $2.5 \mathrm{~mm}$ filter could not be used. Each hole was measured in three places, rotating the sample by $120^{\circ}$. Measurements were taken at a distance similar to the beginning of the hole.

Figures 5 and 6 show the surface roughness measurement results for the holes drilled in the tested composite with MQL of the cutting zone and without the use of machining fluid. It appears from the bar charts that the use of oil mist clearly reduces the surface roughness of the holes drilled at a low feed rate. During dry drilling at a feed rate of respectively $0.05 \mathrm{~mm} / \mathrm{rev}$. and $0.075 \mathrm{~mm} / \mathrm{rev}$. and at a cutting speed of respectively 11 and $44 \mathrm{~m} / \mathrm{min}$ very high $R a$ values of up to $10 \mu \mathrm{m}$ and $R z$ values of up to $50 \mu \mathrm{m}$ were obtained. The high values could be due to build-up formation during drilling. Even though the composite material is harder than the matrix and as the surface layer of the composite is being machined build-up formation is less intensive than during aluminum separation, build-up was observed during the tests. This adverse phenomenon was limited through the use of oil mist during drilling. The largest reduction in roughness $R a$ amounted to $65 \%$ and in $R z$ to $62 \%$. The positive effect of MQL decreases with increasing feed rate. For the adopted highest feed rate of $0.17 \mathrm{~mm} / \mathrm{rev}$. similar or even higher roughness values were obtained for the holes drilled with MQL as for dry drilling. Thanks to the use of oil mist the drilling process stabilizes. The scatter of roughness measurement results after such machining is much smaller than after dry drilling.

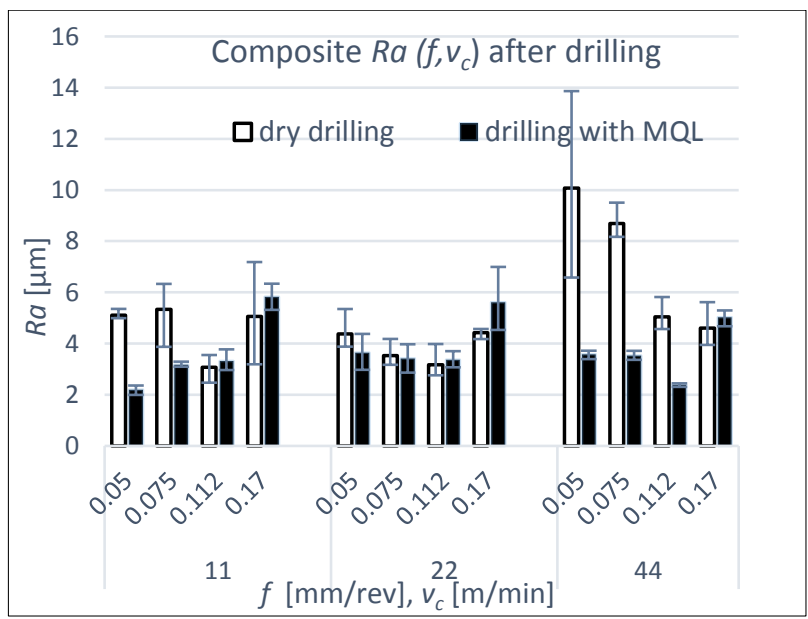

Fig. 5. Surface roughness $R a$ versus feed rate $f$ and cutting speed $v_{c}$ after dry drilling and MQL assisted drilling of aluminum composite material. 


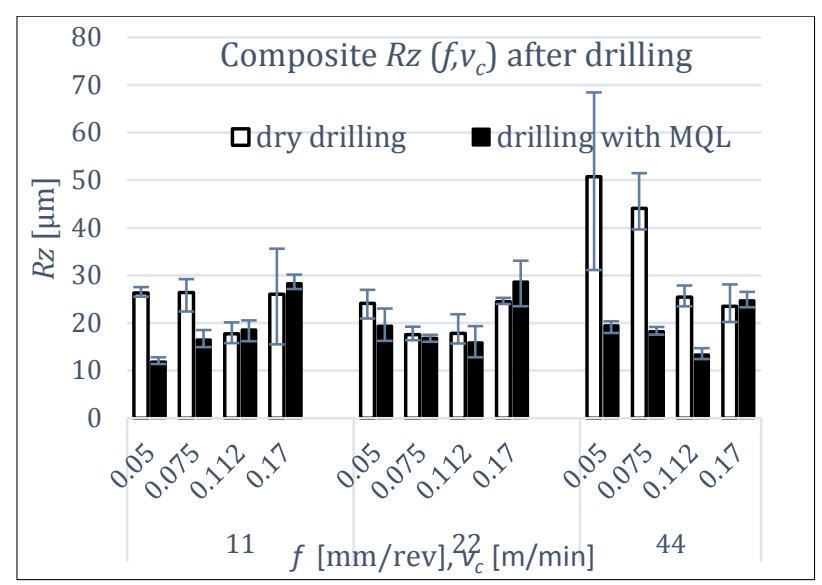

Fig. 6. Surface roughness $R z$ versus feed rate $f$ and cutting speed $v_{c}$ after dry drilling and MQL assisted drilling of aluminum composite material.

A comparison of the roughness measurements for the dry drilled holes in respectively the composite and the aluminum alloy (figs. 7 and 8) shows that the aluminum holes are rougher.

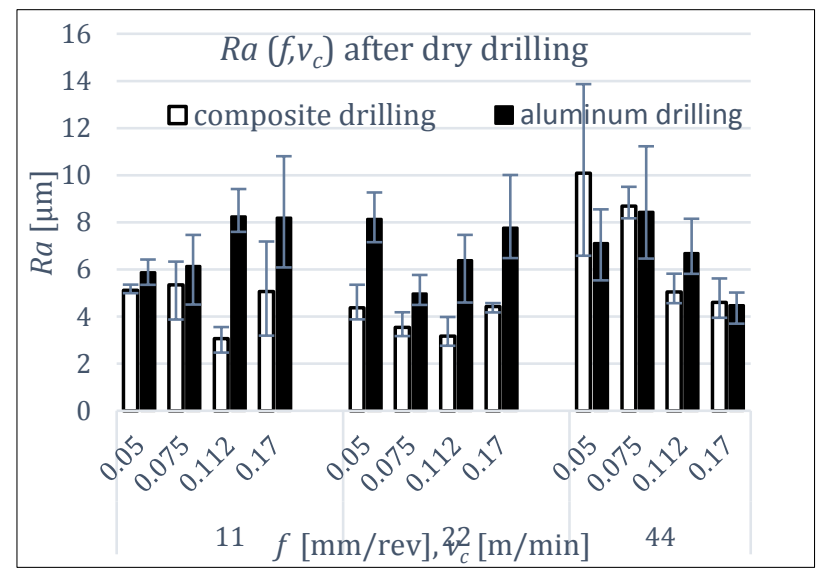

Fig. 7. Surface roughness $R a$ versus feed rate $f$ and cutting speed $v_{c}$ after dry drilling of aluminum composite material and matrix alloy.

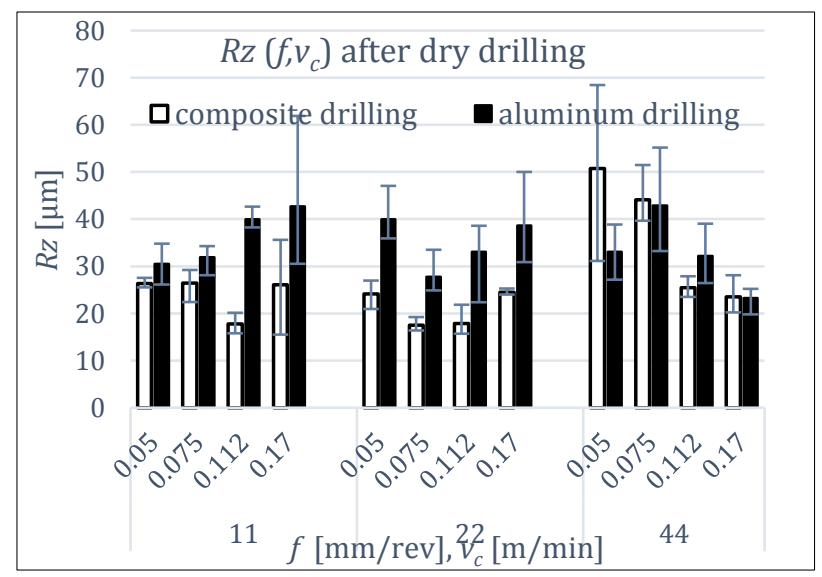

Fig. 8. Surface roughness $R z$ versus feed rate $f$ and cutting speed $v_{c}$ after dry drilling of aluminum composite material and matrix alloy.
The roughness increases with increasing feed rate and decreasing cutting speed. For the speed of 11 $\mathrm{m} / \mathrm{min}$ and the highest feed rates the $R a$ and $R z$ of the aluminum holes are as much as twice higher than those of the composite holes. This is due to a considerable difference in the hardness and plasticity of the two materials, which, in turn, contributes to their tendency towards adhering and sticking to the tool point. Even a small build-up can significantly increase hole surface roughness by disturbing the separation mechanism, generating vibrations and sticking to the surface of the hole after breaking off the drill point. Such broken off buildup also hinders the action of the drill bald patch. For the speeds of $44 \mathrm{~m} / \mathrm{min}$ the differences in hole quality are small and it is even possible to obtain aluminum holes smoother than composite holes. This can be explained by the fact that at this speed the intensity of build-up formation during the drilling of aluminum decreases, whereas the abrasive action of the ceramic reinforcement increases, which may result in the wear of the drill point and in the deterioration of its cutting ability, and consequently in the worse quality of the holes.

The surface roughness of aluminum and composite holes drilled with the assistance of oil mist is compared in figures 9 and 10. For lower feed rates better roughness was obtained in the holes made in the composite. As the feed rate increases so does the roughness of the holes. The increase is higher for the composite surfaces. Hence after drilling at the feed rate of $0.17 \mathrm{~mm} / \mathrm{rev}$. both $R a$ and $R z$ values were lower for the aluminum holes. This means that unlike in the case of the aluminum composites, MQL was observed to have a beneficial effect in the drilling of the aluminum alloy at a high rate of feed.

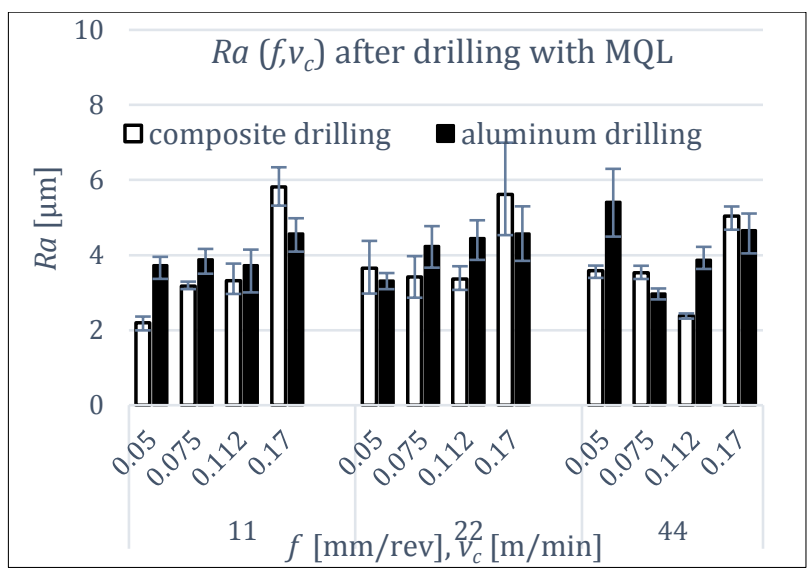

Fig. 9. Surface roughness $R a$ versus feed rate $f$ and cutting speed $v_{c}$ after MQL assisted drilling of aluminum composite and matrix alloy. 


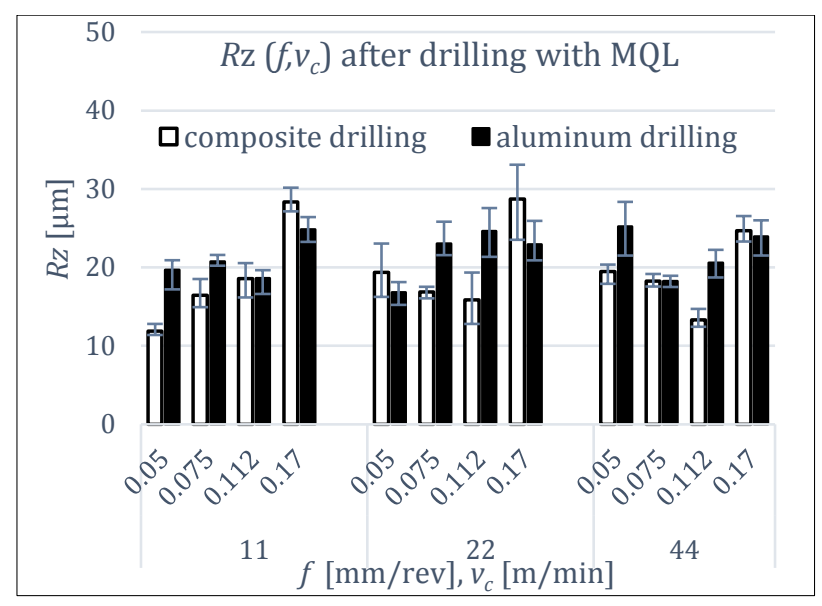

Fig. 10. Surface roughness $R z$ versus feed rate $f$ and cutting speed $v_{c}$ after MQL assisted drilling of aluminum composite and matrix alloy.

The quality of the holes and the necessity of reaming them are determined not only by the surface roughness, but also by the dimensionalshape accuracy. When assessing the possibility and effectiveness of the MQL in the drilling of holes in the composite, the roundness deviation of the holes (fig. 11) and their radial run-out (fig. 12) were measured. It was noticed that in the whole range of machining parameters the deviation of the roundness of the holes drilled with oil-mist assistance decreased. This improvement varied. For the feed rate of $0.17 \mathrm{~mm} / \mathrm{rev}$. the reduction is the smallest, amounting to maximum $25 \%$. For lower feed rates, an improvement of $60-70 \%$ was achieved. In addition, the radial run-out of the holes drilled with MQL was smaller. It appears from the results that the use of oil mist considerably improves the quality of the shape of the drilled holes. In many cases, it was possible to abandon or limit the rough reaming.

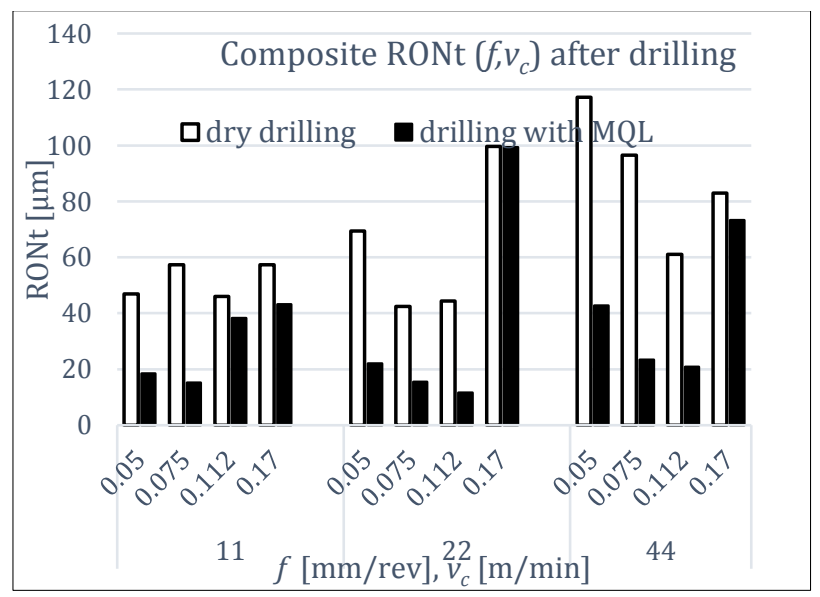

Fig. 11. Roundness deviation RONt versus feed rate $f$ and cutting speed $v_{c}$ for dry drilling and MQL assisted drilling of aluminum composite material.

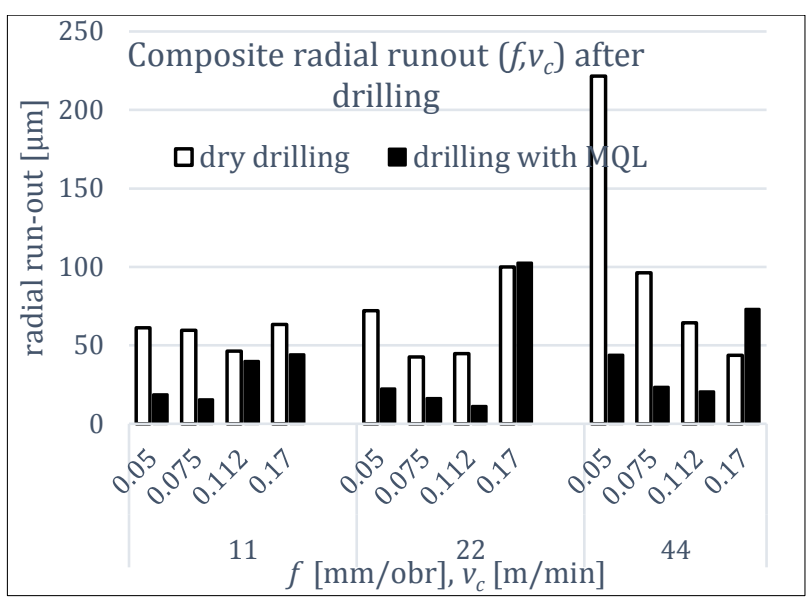

Fig. 12. Radial run-out versus feed rate $f$ and cutting speed $v_{c}$ for dry drilling and MQL assisted drilling of aluminum composite material.

Figures 13-15 show the results of measurements of the feed force during the drilling of composite and aluminum holes. For both materials, regardless of the lubrication conditions, the force increases with the feed, which is consistent with theory. No clear influence of cutting speed was observed. At a fourfold increase in cutting speed the feed force values remain at a similar level. In the whole range of the machining parameters a slight beneficial effect of MQL on the feed force value was observed for the drilling of the aluminum composite. This effect was particularly visible at the lowest feed rates. The maximum reduction in the feed force amounted to $20 \%$. Unlike in the case of surface roughness, no clear influence of MQL on the scatter of force measurement results was observed.

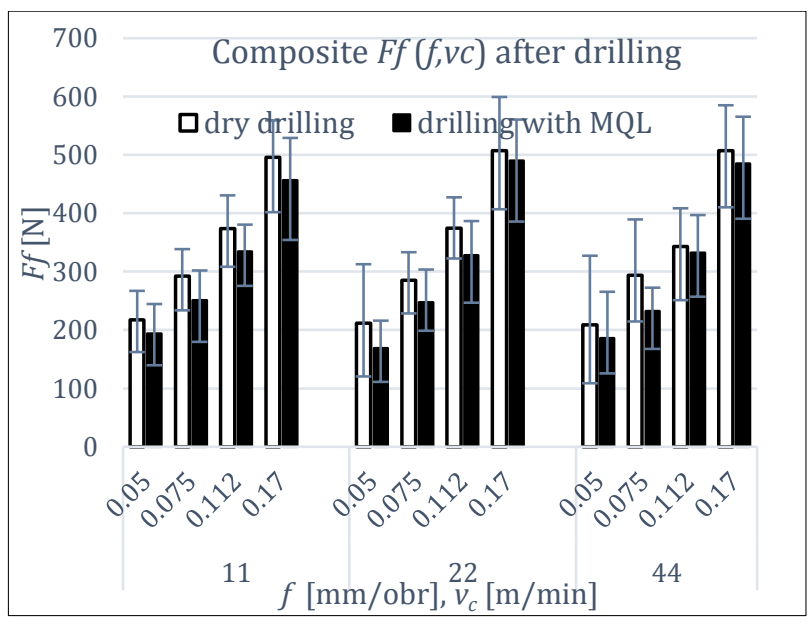

Fig. 13. Feed force $F f$ versus feed rate $\mathrm{f}$ and cutting speed vc after dry drilling and MQL assisted drilling of aluminum composite material. 


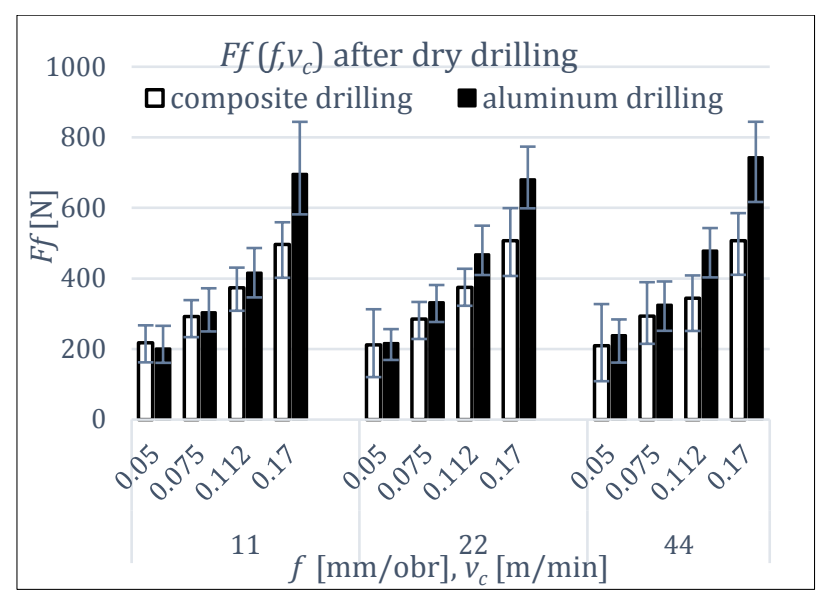

Fig. 14. Feed force $F f$ versus feed rate $f$ and cutting speed $v_{c}$ after dry drilling of aluminum composite material and matrix alloy.

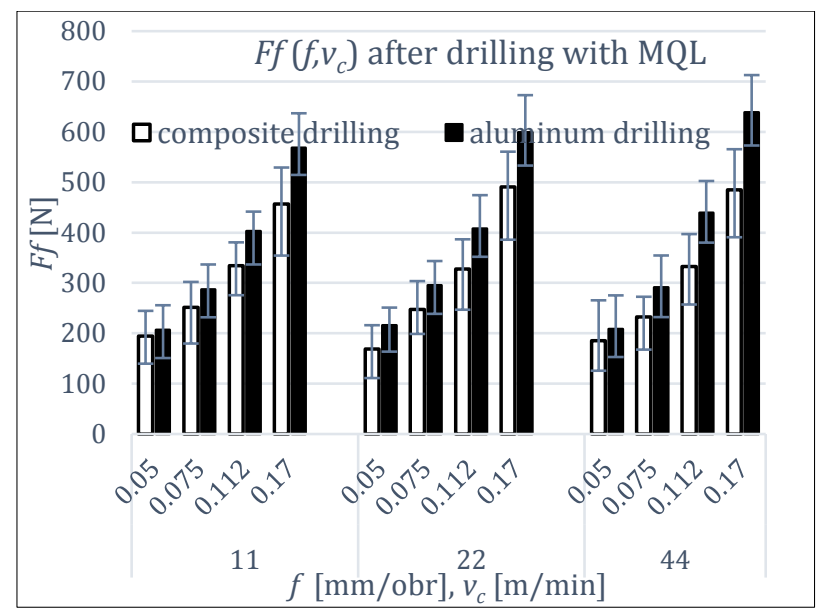

Fig. 15. Feed force $F f$ versus feed rate $f$ and cutting speed $v_{c}$ after MQL assisted drilling of aluminum composite and matrix alloy.

A comparison of the feed force in the drilling of the composite and the aluminum shows that lower cutting resistances occur during the drilling of the aluminum composite. The presence of the hard reinforcement and the greater hardness of the material do not pose such difficulties in machining as the ductile and proneto-flow aluminum sticking to the tool point. The differences in the feed force between the two materials increase with increasing feed rate. The differences were also due to the fact that the same type of drill was used for drilling both the hard composite and the plastic and soft material constituting its matrix.

One of the indicators of the machinability of materials are the chips forming during their machining. The shape and length of chips can be regulated by means of the machining fluid.
However, this applies mainly to the fluid fed under high pressure. MQL can influence the shape of the forming chips only to a small degree. Tables 3 and 4 show photographs of chips which formed during drilling at extreme speed and feed rates. It is clearly apparent that the hardness and plasticity of the machined materials has a marked effect on the length of the chips. As expected, the chips formed during the drilling of the composite are much shorter.

Table 3. Chips forming during dry drilling and MQL assisted drilling of aluminium composite.

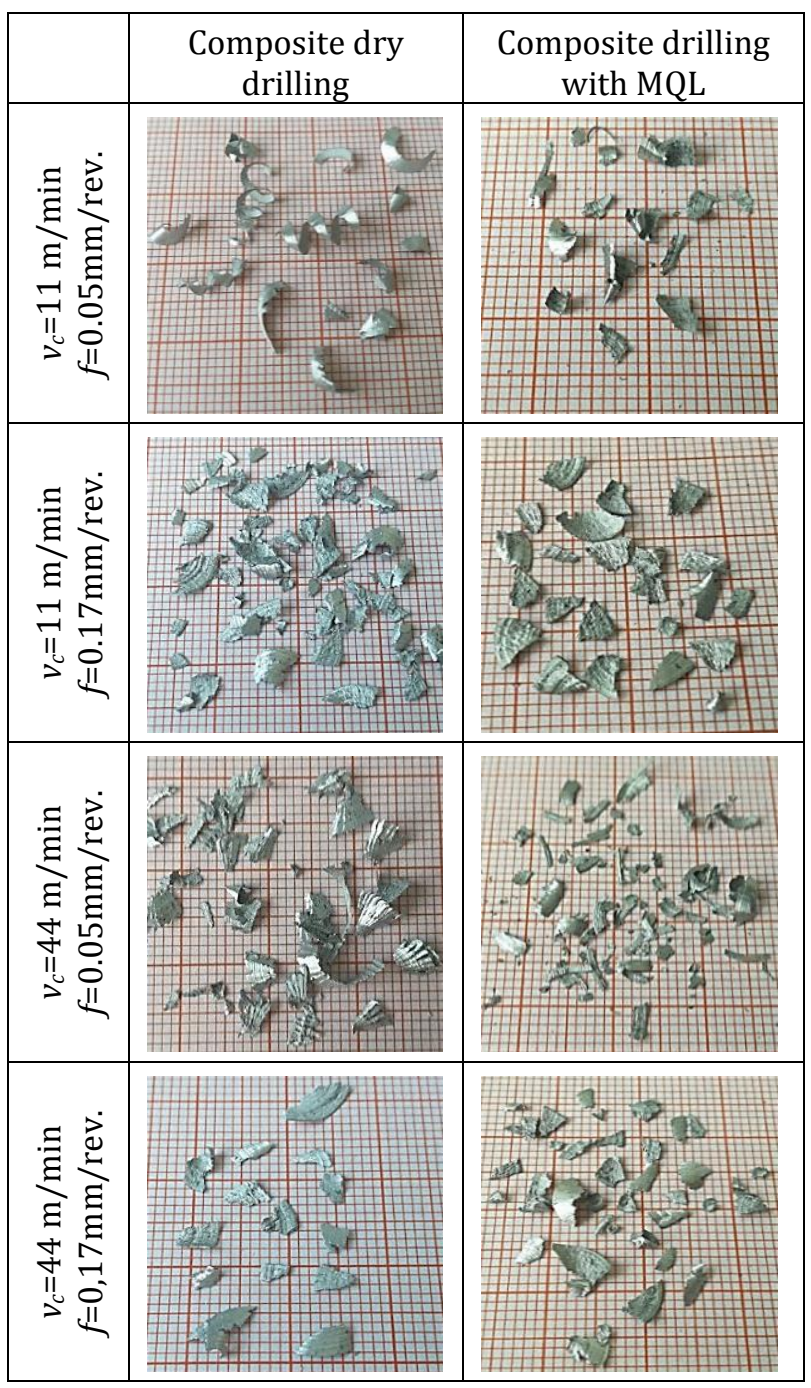

All composite chips are lamellar, broken and short. Longer chips were obtained when drilling aluminum. Additionally as the feed rate increases, the aluminum chips change their form from continuous to segmental. In addition, at lower cutting speed, aluminum chips are thicker and more compressed than composite chips. This phenomenon can be explained by the differences in the plasticity of both materials. For low cutting 
speed, the deformation of the material is slow and the plasticity aluminum alloy has enough time to deform. The situation is different in the case of composite, where the ceramic reinforcement fibers block the deformation of the matrix material deformation. The effect of MQL is small. Both, composite and aluminum chips have a similar shape and length after dry and with MQL drilling. It is possible that a higher oil mist flow rate would have a stronger effect on the shape of the chips. On the other hand, even during dry machining the composite chips are short and do not need shortening, but require only effective removal from the hole being drilled. This removal is essential since cut pieces of the reinforcing fibres occur among the chips, which when in contact with the machined surface could scratch it and increase its roughness. Therefore, the best method is to remove chips from drilling zone with the center of the tool.

Table 4. Chips forming during dry drilling and MQL assisted drilling of matrix of composite.

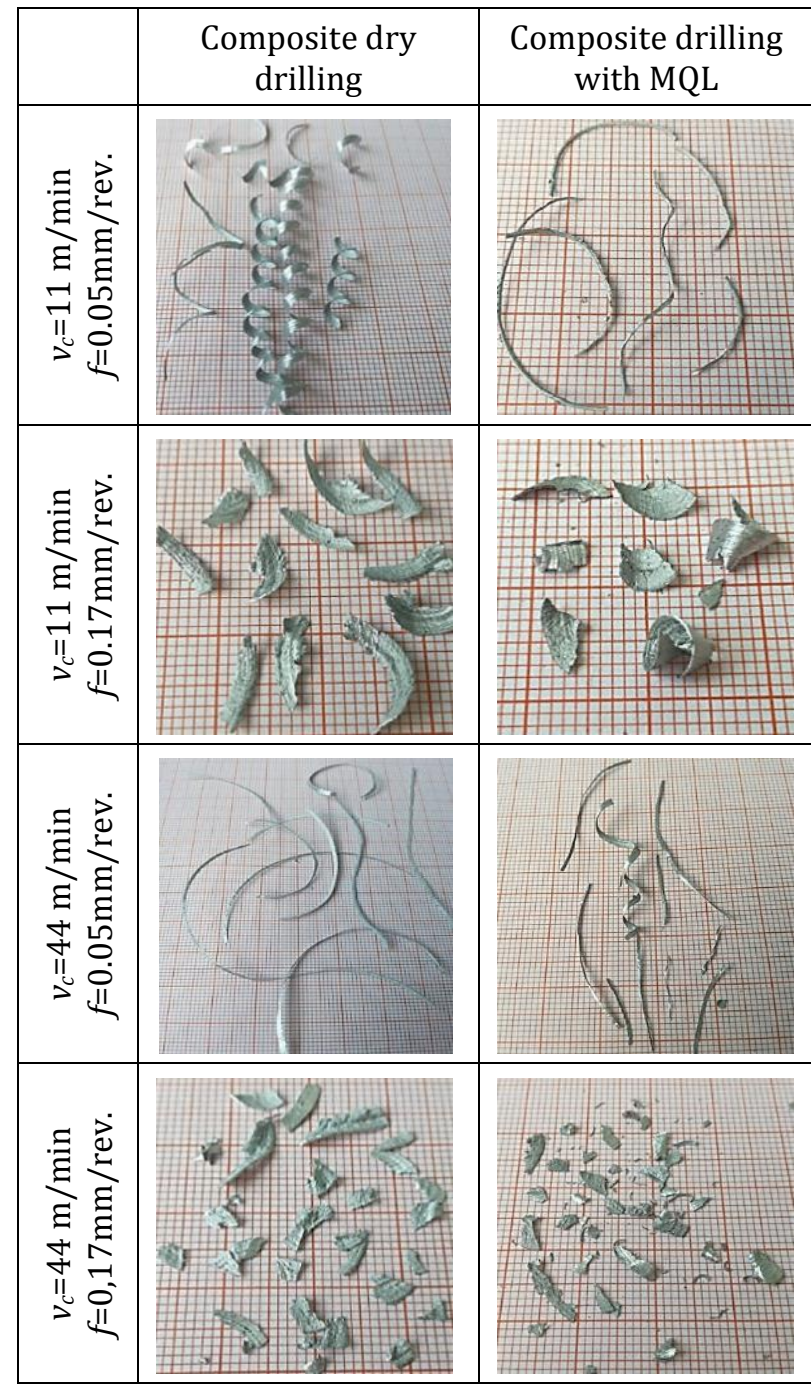

The tested material was a composite developed and manufactured at Wroclaw University of Science and Technology. Until now, machinability, including the applicability of MQL, has been studied on the example of turning [31]. The aim of this research was to assess the possibility of using the minimum quantity of lubrication of the cutting zone and to determine the effectiveness of oil mist in the drilling of holes in metal matrix composites using the example of machining material developed at Wroclaw University of Science and Technology. The article confirms that dry drilling gives the possibility of obtaining holes of average quality. This is due to the high temperature that forms at the cutting edge. In the works [15-18] it was shown that the use of MQL effectively reduces the cutting temperature in the machining of light metal alloys. MQL acts as a coating agent, forming a thin film of lubricant, preventing heat buildup through reduction in friction. The effect is to reduce the intensity of forming build-up on the edge and cutting resistance. The quality of the holes increases. Despite the small amount of liquid, the chips become shorter. The problem is still to remove them from the cutting zone. The positive impact of MQL has been confirmed in this article on the aspect of aluminum matrix composite drilling. There was a reduction in surface roughness, shape error, and drilling force compared to dry machining. Moreover, it has been found that by using the oil mist, it is possible to shorten the chips when drilling the aluminum alloy being the matrix of composite. All this makes MQL an excellent method of lubricating the cutting zone in the machining of difficult-to-cut materials.

\section{CONCLUSIONS}

The results of investigations into the drilling of an aluminium-matrix composite reinforced with long Saffil ceramic fibres have been presented. The aim of this research was to assess the possibility of the use of the minimum quantity lubrication of the cutting zone and to determine the effectiveness of oil mist in the drilling of holes in metal-matrix composites. The surface roughness and shape accuracy of the holes were the investigated machining effects. Also the feed force was measured and the form and shape of the chips were appraised. For comparison, holes were drilled in aluminium alloy AlSi9Mg constituting the matrix of the composite. The effectiveness of MQL assisted drilling in comparison with the dry drilling of 
aluminium alloys is still the subject of numerous studies. The results presented in this paper extend the knowledge on this subject. This research has shown that:

- the use of oil mist markedly reduces (by as much as 65\%) the surface roughness of holes drilled in the composite at a low feed rate;

- the beneficial effect of minimum quantity lubrication decreases with increasing feed rate;

- an additional advantage of the use of oil mist is the smallest scatter of surface roughness measurement results;

- using MQL one can obtain surface roughness $R a$ of $2 \mu \mathrm{m}$, whereas in the case of dry drilling the obtained minimal roughness $R a$ amounted to $3 \mu \mathrm{m}$;

- in comparison with the holes drilled in the matrix material, the quality of the surface of the holes drilled in the composite is higher;

- as the cutting speed increases, the differences in surface roughness $R a$ and $R z$ between the composite holes and the aluminium holes disappear;

- in the whole range of the adopted machining parameters MQL improves the shape quality of the drilled composite holes;

- the beneficial effect of MQL on the roundness deviation of the composite holes decreases as the rate of feed increases; for the feed rates of 0.05 and $0.075 \mathrm{~mm} / \mathrm{rev}$. the improvement amounted to as much as $70 \%$, whereas for the feed rate of $0.17 \mathrm{~mm} / \mathrm{rev}$. it amounted to $25 \%$;

- the use of oil mist has only a small influence (maximally 20\%) on the feed force value during the drilling of the composite and has no influence on the scatter of force values;

- the force measured during the drilling of the reinforced material was smaller than the one measured during the drilling of the aluminum alloy;

- MQL was found to have no effect on the form of the chips produced during the drilling of the composite.

The presented results are only part of a larger study on the machinability of aluminum matrix composites and the use of minimal lubrication of the cutting zone. They show the effect of MQL only when drilling at low cutting speed. In addition, only the effect of external oil mist application was investigated. In furthes tests, the range of used cutting parameters will be extended, an internal oil mist should be used and the influence of MQL on the durability of the blades should be examined.

\section{REFERENCES}

[1] J.P. Davim, Design of optimization of cutting parameters for turning metal matrix composites based on the orthogonal arrays, Journal of Materials Processes Technology, vol. 132, no. 13, pp. 340-344, 2003.

[2] P.S. Bains, S.S. Sidhu, H.S. Payal, Fabrication and machining of metal matrix composites: $A$ Review, Materials and Manufacturing Processes, vol. 31, iss. 5, pp. 553-573, 2016, doi: 10.1080/10426914.2015.1025976

[3] K. Rajkumar, P. Rajan, J. Maria Antony Charles, Microwave Heat Treatment on Aluminium 6061 Alloy-Boron Carbide, Procedia Engineering, vol. 86, pp. 34-41, 2014, doi: 10.1016/j.proeng.2014.11.008

[4] C.R. Dandekar, Y.C. Shin, Modeling of machining of composite materials: A review, International Journal of Machine Tools and Manufacture, vol. 57, pp. 102121, 2012, doi: 10.1016/j.ijmachtools.2012.01.006

[5] S. Sivasankaran, P.T. Harisagar, E. Saminathan, S. Siddharth, P. Sasikumar, Effect of Nose Radius and Graphite Addition on Turning of AA 7075-ZrB2 insitu Composites, Procedia Engineering, vol. 97, pp. 582-589, 2014, doi: 10.1016/j.proeng.2014.12.286

[6] K. Venkatesan, R. Ramanujam, J. Joel, P. Jeyapandiarajan, M. Vignesh, Darsh Jiten Tolia, R. Venkata Krishna, Study of Cutting force and Surface Roughness in machining of Al alloy Hybrid Composite and Optimized using Response Surface Methodology, Procedia Engineering, vol. 97, pp. 677-686, 2014, doi: 10.1016/j.proeng.2014.12.297

[7] S. Arul, L. Vijayaraghavan, S.K. Malhotra, R. Krishnamurthy, Influence of tool material on dynamics of drilling of GFRP composites, The International Journal of Advanced Manufacturing Technology, vol 29, pp. 655-662, 2006, doi: 10.1007/s00170-005-2581-5

[8] T. Rajmohan, K. Palanikumar, M. Kathirvel, Optimization of machining parameters in drilling hybrid aluminium metal matrix composites, Transactions of Nonferrous Metals Society of China, vol. 22, iss. 6, pp. 1286-1297, 2012, doi: 10.1016/S1003-6326(11)61317-4

[9] R. Zitoune, V. Krishnaraj, F. Collombet, Study of drilling of composite material and aluminium stack, 
Composite Structures, vol. 92, iss. 5, pp. 1246-1255, 2010, doi: 10.1016/j.compstruct.2009.10.010

[10] A.M. Abrão, P.E. Faria, J.C. Rubio, P. Reis, J.P. Davim, Drilling of fiber reinforced plastics: $A$ review, Journal of Materials Processing Technology, vol. 186, iss. 1-3, pp. 1-7, 2007, doi: 10.1016/j.jmatprotec.2006.11.146

[11] N. Altinkok, F. Ficici, A. Coban, Determination of optimum particle size of Al203/SiCp reinforced hybrid composites materials in wear testing, Industrial Lubrication and Tribology, vol. 67, iss. 1, pp. 66-74, 2015, doi: 10.1108/ILT-04-2014-0031

[12] A. Nagaraj, A. Uysal, I. S. Jawahir, An Investigation of Process Performance when Drilling Carbon Fiber Reinforced Polymer (CFRP) Composite under Dry, Cryogenic and MQL Environments, Procedia Manufacturing vol. 43, pp. 551-558, 2020, doi: 10.1016/j.promfg.2020.02.165

[13] J. Xu, M. Ji, J.P. Davim, M. Chena, M. El Mansori, V. Krishnaraj, Comparative study of minimum quantity lubrication and dry drilling of CFRP/titanium stacks using TiAlN and diamond coated drills, Composite Structures, vol. 234, pp. 1117-1127, 2020, doi: 10.1016/j.compstruct.2019.111727

[14] C. Kannan, C.H. Varun Chaitanya, Dwarakesh Padala, Likithnath Reddy, R. Ramanujam, A.S.S. Balan, Machinability studies on aluminium matrix nanocomposite under the influence of $M Q L$, Materials Today: Proceedings vol. 22, pp. 15071516, 2020, doi: 10.1016/j.matpr.2020.02.068

[15] Z. Zhu, B. He, J. Chen, Evaluation of tool temperature distribution in MQL drilling of aluminum 2024-T351, Journal of Manufacturing Processes, vol. 56, pp. 757-765, 2020, doi: 10.1016/j.jmapro.2020.05.029

[16] S. Bhowmick, M.J. Lukitsch, A.T. Alpas, Dry and minimum quantity lubrication drilling of cast magnesium alloy (AM60), International Journal of Machine Tools \& Manufacture, vol. 50, iss. 5, pp. 444457, 2010, doi: 10.1016/j.ijmachtools.2010.02.001

[17] F. Berzosa, B. de Agustina, E.M. Rubio, Tool Selection in Drilling of Magnesium UNSM11917 Pieces under Dry and MQL Conditions based on Surface Roughness, Procedia Engineering, vol.184, pp.117127, 2017, doi: 10.1016/j.proeng.2017.04.076

[18] E.A. Rahim, H.Sasahara, A study of the effect of palm oil as MQL lubricant on high speed drilling of titanium alloys, Tribology International, vol. 44, iss. 3, pp. 309317, 2011, doi: 10.1016/j.triboint.2010.10.032

[19] P. Karolczak, M. Kowalski, K. Raszka, The Effect of the Use of Cutting Zone Minimum Quantity Lubrication and Wiper Geometry Inserts on Titanium Ti6Al4V Surface Quality After Turning, Tribology in Industry, vol. 43, no. 2, pp. 321-333, 2021, doi: 10.24874/ti.1077.03.21.05

[20] A. Pal, S.S. Chatha, H.S. Sidhu, Performance evaluation of the minimum quantity lubrication with $\mathrm{Al}_{2} \mathrm{O}_{3}$ - mixed vegetable-oil-based cutting fluid in drilling of AISI 321 stainless steel, Journal of Manufacturing Processes, vol. 66, pp. 238-249, 2021, doi: 10.1016/j.jmapro.2021.04.024

[21] A. Singh, P. Kumar, I. Singh, Design and Development of Electro-Discharge Drilling Process, Advanced Materials Research, vol. 651, pp. 607-611, 2013, doi: 10.4028/www.scientific.net/AMR.651.607

[22] H. Kumar, R. Choudhary, S. Singh, Experimental and Morphological Investigations Into Electrical Discharge Surface Grinding (EDSG) of 6061Al/Al203p 10\% Composite by Composite Tool Electrode, Journal of Materials Engineering and Performance, vol. 23, pp. 1489-1497, 2014 doi: 10.1007/s11665-014-0899-6

[23] R. Choudhary, G. Singh, S. Singh, S. Dhanjal, P. Singh, S. Kathuria, V. Singh, Blind hole drilling of hybrid aluminium-rice husk ash (ARHA) composite using rotary electro-discharge drilling Materials Today: Proceedings, vol 5, iss. 9, pp. 20023-20032, 2018, doi: 10.1016/j.matpr.2018.06.369

[24] S. Marimuthu, M. Antar, J. Dunleavey, Characteristics of micro-hole formation during fibre laser drilling of aerospace superalloy, Precision Engineering, vol. 55, pp. 339-348, 2019, doi: 10.1016/j.precisioneng.2018.10.002

[25] S. Marimuthu, J. Dunleavey, Y. Liu, B. Smith, A. Kiely, M. Antar, Characteristics of hole formation during laser drilling of SiC reinforced aluminium metal matrix composites, Journal of Materials Processing Technology, vol. 271, pp. 554-567, 2019, doi: 10.1016/j.jmatprotec.2019.04.030

[26] L. Dobrzański, Fundamentals of materials science and metal science, WNT, Warszawa, 2002. (in Polish).

[27] K.E. Oczoś, A. Kawalec, Shaping of light metals, Wydawnictwo Naukowe PWN, Warszawa, 2012 (in Polish).

[28] U. Aybarc, D. Dispinar, Aluminium Metal Matrix Composites with SiC, Al203 and Graphene Review, Archives of Foundry Engineering, vol. 18, iss. 2, pp. 5-10, 2018, doi: 10.24425/122493

[29] K. Naplocha, Optimization of technological parameters of the manufacturing process of $A K 9$ materials reinforced with $\mathrm{Al}_{2} \mathrm{O}_{3}$ ceramic fibers, PhD Thesis, Wrocław University of Science and Technology, Wrocław, 1999. (In Polish).

[30] T. Szymczak, Brittle fracture of metal-ceramic composites, Composite Materials, vol. 1, pp. 5357, 2016 (In Polish).

[31] P. Karolczak, M. Kołodziej, M. Kowalski, Effectiveness of diamond blades in the turning of aluminium composites, Advances in Science and Technology Research Journal, vol. 14, iss. 4, pp. 262-272, 2020, doi: 10.12913/22998624/127436 